This manuscript has been submitted for publication in the Journal of Cleaner Production. The manuscript is now being peer-reviewed. Subsequent versions of this manuscript may have slightly different content. If accepted, the final version of this manuscript will be available via the 'Peer-reviewed Publication DOI' link on the right-hand side of this webpage. Please feel free to contact any of the authors. 


\title{
ROLE OF LITHIUM MINING ON THE WATER STRESS OF THE SALAR DE ATACAMA BASIN
}

\author{
by

\section{Juan Ignacio Guzmán ${ }^{1 *}$, Patricio Faúndez², José Joaquín Jara², Candelaria Retamal ${ }^{4}$}

Brines located in the Salar de Atacama are a significant source of lithium

worldwide. The extractive method for these minerals is through brine pumping, with subsequent solar evaporation in ponds. In this latter process, part of the water present in brine is evaporated to the atmosphere, leading to the possibility of harvesting lithium and potassium salts. This situation has risen a series of environmental concerns among local stakeholders and international environmental groups; specifically, in terms of water depletion caused by mining activities. However, no comprehensive studies have been carried out to quantify the impact on the water availability of this basin as a consequence of lithium mining. The aim of this study is to contribute to fill in this gap by quantifying the impact of brine and water evaporation over the precipitations in the area, and thus on the water stress at the Salar de Atacama basin.

Through the implementation of a novel methodology based on a VAR model, the potential recharge on the basin is estimated, considering the precipitations associated with water evaporation in the process of lithium extraction. With this information, the Water Stress Index (WSI) over the period 2002-2017 is computed. The results show that

\footnotetext{
${ }^{1}$ Mining Engineering Department at the Pontificia Universidad Católica de Chile. Email: jguzmanb@puc.cl. Address: Vicuña Mackenna 4860, Santiago, Chile. Tel.: +56 9977646120.

${ }^{2}$ Gestión y Economía Minera Limitada. Email: pfaundez@gem-ing.cl. Address: Av. Las Condes 12.561, tower 3, office 805, Santiago, Chile.

${ }^{3}$ Mining Engineering Department at the Pontificia Universidad Católica de Chile. Email: jjjara@ing.puc.cl. Address: Vicuña Mackenna 4860, Santiago, Chile

${ }^{4}$ Gestión y Economía Minera Limitada. Email: cretamal@gem-ing.cl. Address: Av. Las Condes 12.561, tower 3, office 805, Santiago, Chile.
} 
comparing the factual and a mining-free counterfactual scenario, the extraction of brine would have had a minor impact on the availability of water in the Salar de Atacama basin.

Keywords: Hydrological cycle, Lithium, Salar de Atacama, Solar evaporation, Water Stress Index

\section{Introduction}

Climate change is a natural phenomenon (Scafetta, 2010), boosted by anthropogenic activities related with the emission of greenhouse gases (such as carbon dioxide), which could lead to a generalized disturbance of vital cycles in the world (Kundzewicz, 2008). Whilst the effects of climate change on freshwater resources seem to vary depending on the region (Yang et al. 2019), the hydrological cycles show a generalized tendency to disturbance (Kundzewicz, 2008).

The Battery Electric Vehicles (BEV) revolution responds to a decarbonization era, risen by the worldwide necessity of fighting against climate change (Habib et al., 2020; Sovacool et al., 2020). Hence, a soaring demand for BEV has consequently created a strong incentive to boost lithium supply, as lithium is an indispensable resource for BEV production.

Lithium is currently exploited mainly from two sources: (1) pegmatitic resources and (2) salt flats or salars (Garret, 2004; Kesler et al., 2012). The former exploitation is associated with rock (solid) extraction, while the latter focuses on brine (liquid) pumping. Salars are evaporitic resources which formation relates to the occurrence of precipitation over a saturated brine surface or near surface, hydrologically driven by solar evaporation (Warren, 2016). Historically salt flats have been exploited for the extraction not only of 
lithium and potash but also of borates, hydrocarbons, sodium sulfate, sodium carbonate, calcium chloride, among other minerals (Warren, 2016).

The Salar de Atacama is the largest source of lithium under exploitation in the world, containing approximately a fourth part of global reserves (Marazuela et al., 2019a). It is located $55 \mathrm{~km}$ south from San Pedro de Atacama, at 2300 m.a.s.l. in the Andes Mountains of northern Chile at the Atacama Desert. The Atacama Desert has a hyper-arid climate with an average precipitation of less than $2 \mathrm{~mm} / \mathrm{yr}$ (Finstad et al., 2016). However, this arid tendency is not generalized for the Atacama Desert (Marazuela et al., 2019b). The Salar de Atacama's precipitations are positively affected in magnitude by altitude, reaching more than $120 \mathrm{~mm} / \mathrm{yr}$ in the Western Cordillera flank where elevations above 5,000 m.a.s.1 are attained (Houston, 2006; Marazuela et al., 2019b; Marazuela et al., 2020).

The overall Salar de Atacama's endorheic basin has an area of approximately $17,000 \mathrm{~km}^{2}$ and its long axis is disposed in the N-S direction (see Figure 1) (Marazuela et al., 2020). This flat is the third largest saline pan in the world with a surface area of 3,100 $\mathrm{km}^{2}$ (Marazuela et al., 2020) that has formed through cycles of irregular dry and wet periods. The latter of these cycles, lasted for tens of thousands of years (Bobst et al., 2001) and the phenomenon of solar evaporation has played a major role not only on its formation process (Kampf et al., 2005), but as it is, and has always been, the biggest source of evaporation in the entire Atacama Desert (Finstad et al., 2016).

The salt flat is composed by a nucleus and a marginal or mixing zone (see Figure 2). The nucleus is mainly composed by halite, while the mixing zone is primarily composed by carbonates and gypsum (Vásquez et al., 2013). In the marginal zone, hypersaline wetlands and lagoons are primarily placed on the east zone of the salt flat (see Figure 2). These lagoons are the result of upwelling groundwater that emerges to the surface due to density 
differences between freshwater coming from precipitation recharge and brine (Marazuela et al., 2020).

As the preservation of water bodies enhances the preservation of the living ecosystems in the area, studying the dynamic behavior of the Salar de Atacama in terms of its water cycle is key. Most of the time salars are considered to be static or "fossil", although they are actually in dynamic equilibrium (Houston et al., 2011). Because of this, a significant effort has been done to understand the environmental impact of lithium exploitation in the Salar de Atacama, specially related with the brine and water extraction and their effects on the surrounding hypersaline lagoons and wetlands (DGA, 2013; Amphos, 2018a; Marazuela, 2019a; Marazuela, 2019b, Marazuela, 2020). However, so far no impacts from brine pumping have been identified in these aquatic systems (Munk et al., 2021).

A first step for understanding the effects of the mining activity at the Salar de Atacama over the basin's water cycle is to understand the extraction process. Figure 3 shows a diagram illustrating the current technology used by both companies operating in the Salar de Atacama (SQM and Albemarle). In general terms, brine is pumped and transported using pipelines (where freshwater is required to enhance transportability). The watered brine is deposited in evaporation ponds to harvest potassium and other salts. Once these salts have precipitated the remaining solution is deposited in a new evaporation pond to recover lithium. While potassium salts are processed to produce potassium chloride and other potash compounds, lithium is sent to a treating plant (Salar del Carmen) to produce lithium carbonate and lithium hydroxide. Once the process has concluded, the remaining brine is reinjected in the basin, and its volume is in average a $20 \%$ of the original extracted amount (SQM, 2020). 
The current technology of lithium production in the Salar de Atacama is consequently based on solar evaporation: a natural, residue free process that several authors have stated as cleaner than other technologies available or being used in other operations around the world, which typically depend on the use of more freshwater and chemical additives for lithium extraction (Bian et al., 2017; Calvo, 2019; Liu et al., 2019; Zhao et al., 2019a). However, lithium extraction through evaporation ponds presents a relatively low efficiency in terms of lithium recovery (around 50\%-70\%) compared with solvent extraction, ion-sieve adsorption, electrochemical processes, or membrane technologies that can achieve more than $80 \%$ of recovery (Bian et al., 2017; Calvo, 2019; Liu et al., 2019; Zhao et al., 2019a).

As it was previously detailed, lithium's exploitation process at the Salar de Atacama includes two inputs that contain water among other elements: (1) a brine with more than $170[\mathrm{~g} / \mathrm{L}]$ of total dissolved solids; and (2) freshwater with less than $10 \mathrm{~g} / \mathrm{l}$ of total dissolved solids. Water with solid contents between 10 and 170 [g/L] is categorized as brackish water, but it does not play a preponderant role in the lithium extraction activity; therefore, it is not considered in the analysis. Brine is a non-renewable natural resource at human scale (although water contained in it can possibly be considered as perishable over geological scales ${ }^{5}$ ). However, it must be understood that it is not an available resource for human or animal consumption with current technology due to its high solid's concentration

\footnotetext{
${ }^{5}$ Perishability is a concept coined by Guzmán (2019) to refer to natural resources which generation rate is negative without human intervention. There is no conclusive evidence regarding the perishability of water contained in brines in Salar de Atacama, however, this is potentially the case at the scale of tens or hundreds of thousands of years. The following evidence supports this conjecture: Natural evaporation rates in the nucleus have been estimated in $0.005 \mathrm{~mm} / \mathrm{d}$ and lower in the border at the geological scale (Mardones, 1998), empirical evidence shows that preoperational (before anthropogenic mining took place) brine storage was $-12 \mathrm{l} / \mathrm{s}$ as average (SQM, 2020) and geological studies of other salars in Atacama Desert show this is the expected condition (Finstad et al., 2016).
} 
(Flexer et al, 2018). Therefore, water contained in brine is a relevant source only when the separation process from salts occurs. In this case the process consists of evaporation ponds where water turns to be available as water vapor in the atmosphere. Regarding freshwater that is extracted from aquifers on the same basin, the mining of lithium and potash at the Salar de Atacama consumes in average 180 1/s of freshwater (SQM, 2020).

To date, the extraction of brine at the Salar de Atacama has been carried out only by two companies: Albemarle and SQM. The former started its operations in 1983 under the name of Foote Mineral Company, while the latter started potash exploitation in 1986 and lithium production in 1994. Though the first one has specialized in the production of lithium with scarce potash production, the second one has mined potash, lithium and borates. Both producers rent the property to CORFO, a national agency that owns the mining concessions at the Salar de Atacama. As part of this contract, CORFO has constrained the amount of extractable lithium during the period of rent through a quota.

Nevertheless, not everyone agrees with the form in which lithium extraction has been carried out at the Salar de Atacama. The companies that extract brine from the salt flat have been harshly criticized on public media due to an apparently extensive consumption of freshwater (Deutsche Welle, 2020; Reuters, 2018; BBC, 2019). However, these statements are based on treating brines as freshwater. Consequently, a gap still exists regarding the role that mining activities have played in the generation of hydric stress at the Salar de Atacama basin. Specifically, concerns on the amount of water extracted in lithium mining operations in a desertic region arise as a major issue (Liu and Agusdinata, 2020; Sovacool et al., 2020).

Currently, there is a scientific debate regarding the impact of brines and water extraction on the Salar de Atacama over the basin's hydric equilibrium. Some authors 
suggest that lithium mining leads to the dewatering of hypersaline lagoons surrounding the salt flat and the destruction of its fragile ecosystems (Gajardo and Redón, 2019; Sovacool et al., 2020; Garcés and Álvarez, 2020). Contrastingly, the latest research indicates that the historical reduction of natural evaporation in the Salar de Atacama nucleus, triggered by a gradual drawdown of the water table because of mining activity, have not affected the water heads of the mixing zone and partially compensated the brine extraction, enhancing the preservation of the mixing zone ecosystems (Marazuela et al., 2019a). This is termed to as the "damping effect" by Marazuela et al. (2019a), and it supports the view that the Salar de Atacama is a resilient system in terms of hydrological behavior. In fact, Marazuela et al. (2020) found out that natural evaporation decreases from $12.85 \mathrm{~m}^{3} / \mathrm{s}$ to $10.95 \mathrm{~m}^{3} / \mathrm{s} \mathrm{starting}$ on 1986, when a significant brine extraction commenced. Therefore, results from Marazuela et al. (2020) suggest that the Salar de Atacama dynamics could partially compensate mining activities through evaporation reduction.

Another relevant evidence that supports the damping effect occurring in the basin refers to the measuring of the area covered by lagoons adjacent to the deposit. Tejeda et al. (2003) showed that the presence of evaporation buffers both the variations in the phreatic surface and the maximum discharge rate to the ground surface. Consequently, they report that bordering lagoons to the Salar de Atacama do not undergo any significant changes in size despite variations occurring in freshwater recharge rates. Unfortunately, no recent studies are available for measuring the impact of lithium mining on the hypersaline lagoons.

Despite the efforts made to obtain a scientific response regarding the actual state of water dynamics at the Salar de Atacama basin, no comprehensive studies have been done for understanding the role that mining has had on the hydrological cycle at the basin level. 
Specifically, the evolution of the water cycle at the basin and the impact that brine pumping has had on it is the topic of interest that will be further developed. As the main environmental concern refers to the basin's water stress it is precise to understand not only the role of mining in discharge flows in terms of water consumption, but also the role of mining (if any) in the recharge flows in terms of precipitations.

\section{Salar de Atacama' Hydrological Cycle}

The first step is to understand the components of any basin's water balance equation of hydrology (Hölting and Coldeway, 2019), without changes in stock ${ }^{6}$, which corresponds to:

$$
\dot{h}_{P}=\dot{h}_{E}+\dot{h}_{R}+\dot{h}_{D}
$$

Where $\dot{h}_{P}$ refers to the precipitation rate, $\dot{h}_{E}$ evaporation (or more generally evapotranspiration) rate, $\dot{h}_{R}$ is the surface runoff rate and $\dot{h}_{D}$ is the discharge rate.

Based on equation (1), Figure 4 shows the conceptual hydrological cycle in the Salar de Atacama basin. The hydric discharge rate associated to mining activities is generally easy to establish, since companies extracting water from the Salar de Atacama report the extracted amount to the environmental authorities. Additionally, the impact of the lithium mining in both the surface runoff rate and freshwater evaporation is expected to be null or negligible. However, the role of lithium mining on the precipitation rate is less clear.

\footnotetext{
6 The assumption that the water stock at the Salar de Atacama basin do not change significantly over a short period of time is reasonable when brines are not treated as freshwater, which by the reasons before exposed seem sensible.
} 
Therefore, the primary focus of this paper is to assess the effect of lithium mining on this variable.

Brine extraction occurs in two different aquifers (A and B, separated by an aquitard), where theoretically all evaporated water should be returned in the form of precipitation, although not necessarily to the same basin. From the basic equation of hydrologic balance, it is not clear whether part or all the evaporated water from lithium mining ponds is returning to the Salar de Atacama basin. This uncertainty arises since equation 1 is valid for closed systems. Therefore, while this is a good assumption for groundwater, it is not necessarily straightforward for water vapor or moisture in the troposphere associated with water evaporated from the basin.

Some authors recognize, either for a hydrological basin or a couple of them, the local effect that evaporation has on precipitation, although without considering anthropogenic effects in our knowledge (Kong et al., 2013; Seneviratne et al., 2010; Zongxing et al., 2016; Zhao et al., 2019b). Still, there are no articles describing the anthropogenic effect on precipitations due to changes in land evaporation from mining of any mineral. Nonetheless, some authors recognize the impact that other anthropogenic activities can have on precipitations due to: (1) aerosol emissions (Bai et al., 2020), (2) greenhouse emissions and (3) land use (Umar et al., 2019). Additionally, there is a significant support to the view that different human activities (particularly land use and dam constructions) may alter the hydrological cycle at a basin scale (Awotwi et al., 2017; Elsanabary and Gan., 2015; Shao et al., 2020; Van der Ent, 2010; Wang et al., 2008).

There are many factors that influence the occurrence of local precipitations due to local evaporation (or evapotranspiration if vegetal transpiration is counted). These factors include climate, topography, water body areas, soil moisture content, vegetation coverage, 
plant species and human activities, all of them at a local level (Zongxing et al., 2016; Zhao et al., 2019b). Evaporation and precipitation are intrinsically related with soil moisture and temperature. The resulting interaction among all these four variables can be characterized as a dynamic complex system. Ultimately, precipitation intensity is not only defined by water contribution from evaporation but, it is also affected by changes in the rest of variables as a response to changes in evaporation (Seneviratne et al., 2010).

The evapotranspiration contributions to local precipitation depends on the basin's climate. In poorly vegetated areas, the evaporation would have a higher contribution to precipitation than transpiration. Instead, in an overly vegetated area the transpiration contribution will prevail over the evaporation contribution (Kong et al., 2013; Zongxing et $a l ., 2016)$. Evapotranspiration can also have a seasonal contribution that differs between summer or winter times (Zongxing et al., 2016). Contribution of evapotranspiration at a local scale seems to be different and specific for each geographical area. For example, this fraction has been found to be $23 \%$ for Shiyang inland river basin in China (Zongxing et al., 2016), 5\%-16\% in the Great Lakes region (Gat et al., 1994; Machavaram and Krishnamurthy, 1995), 3\% in Alpine regions (Froelich et al., 2008) and 37\% and 31\% in plain and foothill regions of Taiwan, respectively (Peng et al., 2011).

\section{Methodology and data}

A total of 12 weather stations in the basin are considered (Figure 1). These stations are monitored by the two main lithium extracting companies in the Salar de Atacama (SQM and Albemarle) as well as the DGA (the water governmental agency in Chile) and the Institute for Agricultural Research (INIA). Precipitations per each weather station are 
available at a monthly basis from January 1986 to December 2018, where a heterogenous behavior is observed (Figure 5), as precipitations are more abundant in the northeast sector of the basin compared to the nucleus or south section of the salt flat. Figure 5 shows that precipitations are not only spatially heterogenous but also seasonal within a year (with higher precipitations registered during summer because of the "Altiplanic winter" phenomenon). However, no clear long-term trend for precipitations is observed.

It is difficult to determine the contribution that brine evaporation in ponds has had over the registered precipitations at the Salar de Atacama basin (Flexer et al., 2018). This difficulty is explained due to the complex dynamics of the causality mechanisms between the involved phenomena, the presence of unobserved variables during the period of study such as natural evaporation of the salt flat or other climate variables, as well as the necessary modelling of the Salar de Atacama within a much bigger area in order to understand advective phenomena in the troposphere (including also regional climate processes such as El Niño and La Niña).

Although evaporation from brine extracted in the mining of lithium and potash was not available, the total monthly extraction of brine was provided by SQM for the period January 1983 to December 2018, covering the period of brine extraction for both companies operating in the Salar de Atacama. In Figure 6 it is shown that brine extraction has increased over time, to produce more potash and lithium. Since brine evaporation cycle in ponds takes less than two years since brine extraction is performed (Flexer et al., 2018), this variable should be highly correlated with evaporation if a time lag smaller than two years is considered. Therefore, brine extraction will be used as a proxy variable for water evaporation from brine ponds. 
The response of brine evaporation, henceforth represented by brine extraction with a lag, to precipitation variability per each weather station was evaluated using a nonstructural vector autoregression (VAR) model. The use of this multivariate statistical technique has been applied in literature to determine the cause-effect relationship at a local scale of different climatological variables, including: (1) temperature and soil humidity (Feng et al., 2019), (2) precipitation and soil moisture (Salvucci et al., 2002), (3) groundwater level dynamics (Mangiarotti et al., 2012), (4) temperature, precipitation, humidity and wind speed (Ramli et al., 2019), (5) groundwater level and local precipitations (Russo and Lall, 2017) and (6) groundwater level, precipitations and temperatures (Sasikumar and Indira, 2019), among others.

The VAR model makes it possible to test statistical causality among all different variables. The principle behind this model is that if there is a phenomenological causality among the variables, then there should also be a statistical causality. However, it is important to note that the reverse implication is not necessarily true. Although an interesting approach would be studying the causality of precipitations among weather stations, a crucial purpose of this investigation is to determine whether brine extraction explains part of the precipitations occurring in Salar de Atacama basin.

\subsection{Data collection}

The brine extraction rate at a monthly basis is presented in Figure 6, disaggregating the extraction rate of the two firms exploiting the Salar de Atacama. The average extraction of brine totals $2,192,813 \mathrm{~m}^{3} / \mathrm{month}, 87 \%$ of this amount is extracted by SQM (which processes the brine to recover lithium and potash), while the remaining $13 \%$ is extracted by Albemarle (which only recovers lithium). As reinjected brine is negligible in terms of 
volume content compared to the extracted brine (20\%) (SQM, 2020), it is not considered as a proxy variable for evaporation.

It is important to emphasize, as it was previously explained, that there is no register for natural evaporation, and in fact there is a significant source of uncertainty related with this variable (Marazuela et al., 2020). Although a damping effect has been lately recognized (Marazuela et al., 2019a; Marazuela et al., 2020), related to the fact that a decrease on natural evaporation at the salt flat has occurred due to the anthropogenic mining activity, more research in the estimation of natural evaporation is needed to include this effect on the analysis.

For precipitation characterization, an inventory of weather stations with existing precipitation records in the Atacama Salar basin is carried out. The available data has a monthly frequency. Still, for some weather stations and during certain months data was not registered. When this was the case, SQM filled missing data with their own estimates, based on linear regressions constructed through the precipitation registers on close weather stations in terms of isohyets. Even though there is no available data for precipitations during the period between January 1983 to December 1985, brine extraction during this time window was scarce, averaging $110,756 \mathrm{~m}^{3} /$ month in comparison with upcoming extractions that average 2,382,091 $\mathrm{m}^{3} /$ month, as shown in Figure 6.

Finally, it is important to acknowledge that due to the lack of information reported from the Monturaqui station, this series is treated differently from the rest. SQM (2020) estimated it as an extrapolation from the Socaire station, which is located in a similar isohyet. Hence, the Monturaqui station is not included in the VAR model, but it is considered in the analysis and in the impulse-response model that is presented in the following sections. 


\subsection{VAR Model}

A univariate data analysis is carried out as a first step to understand the behavior of the series being modelled (Lütkephol, 2006; Killian and Lütkephol, 2017). In this scenario, the Augmented Dickey-Fuller test is performed separately in each precipitation series, with the purpose of analyzing their individual stationarity. A multivariate data analysis is the second step. Therefore, the Johansen cointegration test (Lütkephol, 2006) is carried out for different combinations of intercept and trend, in order to assess if the variables have a common stochastic tendency.

Afterwards, the VAR model is performed. In this step two important issues must be corrected before developing the model in order to obtain the desired results: (1) the nonstationarity of brine extraction must be corrected through the inclusion of an additional lag as suggested by Toda and Yamamoto (1995); and (2) the seasonality of the data must be managed by transforming the original series via X12 seasonal adjustment. By performing the latter correction, if no qualitative difference is found in results, then no seasonal adjustment of the series should be done since the inclusion of seasonal adjustment generates a biased and inconsistent coefficient result (Hylleberg, 1986).

Consequently, a VAR process of multivariate time series data is developed to model the relationship between the precipitation series and brine extraction rate. The basic $p-\operatorname{lag}$ VAR model is shown in equation (2) and it is solved through the implementation of ordinary least squares (Lütkephol, 2006; Killian and Lütkephol, 2017). Different lag criteria (Likelihood Ratio, LR; Final Prediction Error, FPE; Akaike, AIC; Schwarz Criterion, SC; Hannan-Quinn, HQ) is used to estimate the lag $p$ in all the available precipitation time series. 


$$
Y_{t}=v+A_{1} Y_{t-1}+A_{1} Y_{t-2}+\cdots+A_{p} Y_{t-p}+\varepsilon_{t}
$$

From equation (2), $Y_{t}$ and $v$ are 12 vectors of times series variables, $t$ represents time (monthly), $A_{j}$ is a $12 \times 12$ coefficient matrix and $\varepsilon_{t}$ is the vector that contains the 12 errors associated with the adjustment for each time series variable.

After coefficient estimations of the VAR model are obtained via ordinary least squares, a stability test is carried out. For assuring the stability of results, all the inverse roots of the autoregressive (AR) characteristic polynomial should be found within the unit circle (Lütkephol, 2006).

The response in precipitations is obtained by using a standard deviation unit impulse in the brine extraction rate. Errors are estimated through analytic methods since the large data observations available assures an asymptotic behavior.

For enhancing a better understanding of the analyzed scenarios, the term counterfactual will be henceforth used for referring to the hypothetical estimations done for the case in which no lithium and potash exploitation (i.e., brine extraction) is performed during the analyzed period. Similarly, the term factual will be used for referring to the estimations done for the case in which lithium and potash exploitation is performed at its actual level during the analyzed period (i.e., the real-life scenario). It is important to acknowledge that the factual scenario considers the total water discharge in the basin occurring through brines evaporation and water consumption. The response of precipitations due to the brine pumping impulse is subtracted from the real precipitation series, obtaining through this procedure the precipitations of the counterfactual scenario.

In order to measure the impact on the basin's hydrology it is necessary to calculate the counterfactual recharge in terms of the factual recharge. According to estimates 
provided by SQM's hydrogeologists in a personal communication to the authors, the approximate water recharge in the basin for the period January 1983 to December 2018 for different changes in precipitations in the same basin in a range going from $-40 \%$ to $+20 \%$ regarding actual levels. Figure 7 shows the basin recharge response to changes in precipitations coming from SQM estimates. Assuming a linear response to precipitations in each weather station (since other functional forms show a more erratic behavior outside the sensibility range of Figure 7), the adjustment factor for recharge was estimated for the counterfactual scenario of no mining.

\section{$\underline{3.3 \text { Water stress of the Salar de Atacama's basin }}$}

As it was previously discussed, information regarding the hydrologic balance condition on the Salar de Atacama is scarce and not yet fully developed on literature. Fortunately, it is possible to quantify the water stress for the Salar de Atacama hydrological basin through the water stress index (WSI) introduced by Smakhtin et al. (2004). This metric constitutes an indicator of water scarcity, which basically consists on the ratio between water usage (withdrawn water) and water availability according to equation (3).

$$
\text { WSI }=\frac{\text { Withdrawn water }}{\text { Water Availability }}
$$

The numerator in (3) can also be defined as the water consumption instead of withdrawn water. Nevertheless, in literature it is mainly interpreted as water usage (Aitken et al., 2015; Nilsalab et al., 2016). Since it is highly non-trivial to quantitatively differentiate water usage from water consumption, a corrected measure of WSI is the $W S I_{e}$, which is defined as shown in equation (4). The idea behind this correction is to include the ecological relevant requirements in the area in order to adjust the availability of withdrawn water. 


$$
W S I_{e}=\frac{\text { Withdrawn water }}{\text { Water availability-EWR }}
$$

The main difference between $W S I_{e}$ and $W S I$ is that the former considers that available water for usage is adjusted by the environmental requirements $(E W R=$ Environmental water requirements).

According to Smakhtin et al. (2004) the stress level measured by the $W_{S I}$ can be classified as slightly exploited $\left(W S I_{e}<0.3\right)$, moderately exploited $\left(0.3 \leq W S I_{e}<0.6\right)$, heavily exploited $\left(0.6 \leq W S I_{e}<1\right)$ or overexploited $\left(W S I_{e}>1\right)$. While the overexploited refers to a depletable condition, a heavily exploited water stress index is associated with an environmentally stressed basin.

The $W S I_{e}$ numerator corresponds to water consumption rate in the basin. Therefore, to assess the $W S I_{e}$ for the Salar de Atacama basin, it is necessary in the first place to consider the available estimations of water consumption in activities that contribute to water depletion in the basin. The water consumption estimations for: (1) touristic and domestic water use, (2) copper producing industries and (3) lithium producing industries were extracted from Liu and Agusdinata (2020), Amphos (2018b) and SQM (2020)․

Analogously, the $W S I_{e}$ denominator comes from subtracting the environmental requirements and runoffs (DGA, 2013) to the total water entering the basin, resulting in a water availability of $2,730 \mathrm{l} / \mathrm{s}$, which is assumed to be constant over time (results are not sensitive to small changes in this value). Although this assumption is a simplification, there are some indicators that could suggest that water availability has been relatively constant in the last decades. For example, precipitations on the basin have not clearly diminished or

\footnotetext{
${ }^{7}$ Information for Albermarle water consumption was extracted from Amphos (2018b).
} 
increased over time. Due to the available data, only the periods 2002-2017 is considered for water stress calculations.

To proceed with the $W S I_{e}$ estimation, some problems associated with the data are corrected. In concrete, the series used by Liu and Agusdinata (2020) for water consumption by touristic use and lithium mining presents two drawbacks. The first one is that authors consider that evaporated water in brine is of the same nature as freshwater (Liu and Agusdinata, 2020, p.2); hence, evaporated water is accounted as water consumed by lithium mining. As it was discussed previously, brine cannot be considered as water for any useful purposes (domestic, agricultural, or industrial), at least during the period of analysis. Yet, it is a source of vapor that could contribute to local precipitations. That is why lithium mining water consumption calculated by SQM (2020) and Amphos (2018b) is used instead of the data estimated by Liu and Agusdinata (2020). A second shortcoming on the Liu and Agusdinata (2020) data is that touristic consumption estimation assumes that tourists stay only one day at the Salar de Atacama (Liu and Agusdinata, 2020; p.5), while the average stay in San Pedro de Atacama (the town located in the basin) is 5.2 days (Subsecretaría de Turismo, 2018). To calculate the water stress index $\left(W S I_{e}\right)$ this correction is introduced. On the other hand, for the counterfactual scenario water consumption associated to lithium mining is not considered, and the water availability is corrected by subtracting the average recharge response (via precipitations) to the brine pumping impulse. Moreover, for the counterfactual scenario a high (P97.5 of the response recharge) and low (P2.5 of the response recharge) estimations are calculated.

\section{Results}




\subsection{Precipitations response to brine extraction}

To understand the causality between brine extraction and precipitation series, a Granger causality test is carried out. The results show that: (1) 10 of the 12 weather stations (except for Peine and KCL) present statistical causality à la Granger $(p<0.05)$ (Granger, 1969); (2) causality between weather stations cannot be rejected with a p-value of $p<0.15$; and (3) no causality is found between precipitations and brine extraction $(p<0.10)$, as expected.

The univariate data analysis is carried out by studying the stationarity of each precipitation series. This is performed through the Augmented Dickey-Fuller test, obtaining the following results: (1) stationarity is rejected for all 12 precipitation series but not for brine extraction rate at a $10 \%$ of significance, where an integrated process of order $1, I(1)$, is identified and (2) seasonal behavior is not rejected for all the model variables at a confidence level of $95 \%$.

By performing the VAR model corrections previously indicated, no qualitative differences are found in the results after performing the inclusion of an additional lag (Toda and Yamamoto, 1995). Regarding seasonal adjustments no qualitative results are derived, so no adjustment for this is done.

The basic $p$-lag VAR model was previously shown in equation (2). Different lag criteria is used to estimate the lag $p$ in all the available precipitation time series, the results show that the LR estimation results in 1 lag. Since brine extraction rate corresponds to a non-stationary variable, a lag of 2 months is finally chosen, following the suggestion of Toda and Yamamoto (1995). This decision was taken after a sensitivity analysis was performed by increasing the lag to 3 and 4 months, which shows that these changes do not 
qualitatively affect the results. Hence, for weather station $i(i=1, \ldots, 11)$ the regression is given by equation (5), where $y_{11, t}$ refers to brine extracted during period $t$.

$$
\begin{gathered}
Y_{i, t}=c_{i}+\alpha_{1,1}^{i} \cdot y_{1, t-1}+\alpha_{1,2}^{i} \cdot y_{2, t-1}+\cdots+\alpha_{1,11}^{i} \cdot y_{11, t-1}+\cdots+\alpha_{1,1}^{i} \cdot y_{1, t-2}+ \\
\cdots+\alpha_{1,11}^{i} \cdot y_{11, t-2}+\varepsilon_{i, t}
\end{gathered}
$$

Where $Y_{t}$ is a vector of 11 times series variables ${ }^{8}, t$ represents time (monthly), $A_{j}$ is a $11 \times 11$ coefficient matrix with $\alpha_{i, j}$ values, $\varepsilon_{t}$ is the vector that contains the 11 errors associated with the adjustment for each time series variable and $c_{i}$ is the vector that contains the constants for each time series variable.

The model coefficients suggest the following results ${ }^{9}:$ (1) the response of precipitations is larger within the first year after brine is extracted; (2) the maximum response occurs between 3 to 4 months after the extraction; and (3) a lag of dynamic correlation is found, which extends the precipitation response up to 24 months after the brine extraction has taken place on some weather stations (Figure 8a). These average results coincide with the 2-year evaporation cycle of brine in operational ponds as it was previously discussed (Flexer et al., 2018). Moreover, precipitation responds at a maximum during the second quarter after brine extraction has taken place, suggesting that water evaporated during this period is also the largest. A highlight of the findings is presented on Figure 8.b, which shows the response of precipitations to brine extraction within a confidence level of $95 \%$. In this case 10 of the 11 weather stations have a positive response (i.e., increase in precipitations) to an increase on brine extraction rate, occurring between 4

\footnotetext{
${ }^{8}$ After making adjustments for lags, each series contained a total amount of 394 observations, which can be considered as a large sample (Lütkephol, 2006).

${ }^{9}$ As it was previously indicated, the VAR model only considers 11 of the 12 total stations, due to Monturaqui's special estimation conditions
} 
and 18 months after the extraction has taken place $(p<0.05)$. Only in the case of El Tatio station the positive response is significant between 4 and 5 months later $(p<0.05)$.

Additionally, the response is also heterogenous among different weather stations. There is a high Pearson correlation between the isohyet of each station and its maximum response during the fourth month after brine extraction $(\rho=0.92)$, (most weather stations achieved the maximum response). Since higher isohyets are found upper in the Andes mountains, the results suggest that water evaporated in the nucleus of the salt flat (where mining and evaporation of brine take place) mostly precipitates in the North-East zone of the Salar de Atacama basin where higher altitudes are found.

The VAR model also allows to assess the precipitations for each weather station under the counterfactual scenario of no mining operations (i.e., no brine extraction). The total response to the impulse of brine extraction in the period from January 1986 to December 2018 suggests that in average a $20.5 \%$ (or $8.6 \mathrm{~mm} / \mathrm{month}$ ) of total precipitations registered at the Salar de Atacama basin would have been contributed by the extracted brine evaporation linked with the mining of lithium (and potash). With a confidence level of $95 \%$ $(p<0.05)$ the VAR model indicates that, considering the basin as a closed system (which does not necessarily illustrate the real dynamic of the system), at least $1.2 \%$ and as much as $39.8 \%$ of total precipitations in the Salar de Atacama basin could be attributable to the mining activity of brine extraction. Besides, the basin recharge could have been between 69 1/s to $1,3751 / \mathrm{s}$ lower in the counterfactual scenario of no mining at the Salar de Atacama $(7231 / s \text { in average })^{10}$.

\footnotetext{
${ }^{10}$ The great differences between the high and low estimates are related with the variability in brine extraction throughout the selected timespan. Hence, higher values appear on recent years as extraction has significantly increased during the past decade.
} 


\subsection{Water stress in the Salar de Atacama}

Regarding the water stress on the basin, which is a fundamental part of this analysis, in Figure 9 the $W S I_{e}$ between 2002 and 2017 is shown. This index was calculated for the average, high and low estimates for the counterfactual scenario recharge response. The high and low estimates are not to be calculated on the factual scenario since this case is not estimated but calculated based on real data coming from DGA (2013), Liu and Agusdinata (2020), Amphos (2018b) and SQM (2020). In average, the factual scenario presents a $W S I_{e}$ of 0.6 with a positive slope of 0.019 per annum. Whilst the counterfactual scenario presents for the low, average and high estimate a $W S I_{e}$ of $0.55,0.73$ and 1.09 and a growing slope per annum of $0.016,0.021$ and 0.031 , respectively.

\section{Discussion}

These results lead to the existence of a positive feedback between mining activity and water recharge which had not been previously discussed in literature. This opens the possibility of producing water from extracted brine through solar evaporation, which could contribute to a partial destress of the already stressed water environment in the Salar de Atacama.

If the Salar de Atacama is considered a closed system, the evaporated water (in average $647.22 \mathrm{l} / \mathrm{s}$ in the period of study) is 2.7 times higher than the maximum permitted freshwater to be consumed in the process of lithium and potash production.

The presented evidence suggests that mining of lithium and potash at the Salar de Atacama might be considered as "exohydric" at a human time scale (at a geological time scale, the water contained in salars might be evaporated anyway), as it enables the possibility of transforming a brine which is non-usable for human activities into freshwater 
in the form of precipitation. This is a new acknowledgement that had not been previously discussed as a potential positive consequence attributable to the extraction or processing of minerals. However, it requires further investigation as long-term brine extraction could have other consequences that are not incorporated in this study.

Finally, it is also noticeable that water separation from brine is present in some technologies under conceptual development for extracting the water to be used in domestic or agricultural applications (Baspineiro et al., 2020; Flexer et al., 2018). However, these technologies are not currently economical, since mechanical separation is an expensive procedure. Still, evaporation ponds have shown to lead to water recovery in the form of recharge through a cost-free, natural procedure. The main differences between these processes are: i) the necessary timespan for achieving the separation; and ii) the water recovery rates, which are known for the technologies under development but more research is required to be clearly evaluated in the natural process.

\section{$\underline{5.1 \text { Hydric stress at the Salar de Atacama basin }}$}

These findings, contrary to the common view, suggest that lithium mining activities could have contributed to destress the water availability in the Salar de Atacama basin by triggering an excess on precipitations in comparison with a mining-free scenario. Through the calculation of the $W S I_{e}$ (Figure 9) in both the factual and counterfactual scenarios, the following conclusions can be driven: (1) for any period, and considering the average counterfactual scenario, the factual scenario always presents a lower stress value than its counterpart; (2) there has been a consistent increase on the basin's water stress over time, regardless of the scenario; (3) the basin has passed from moderately exploited in 2002 to heavily exploited in the last years; and (4) only in the high estimate of the counterfactual 
scenario the basin seems to have experienced an overexploitation status during the last years.

When comparing the averages of the factual and counterfactual scenarios it is possible to assess that not only the factual scenario is less stressed that the counterfactual scenario (21.7\% of difference in the $2002-2017$ period) but also the trend associated to the soaring rate is lower in the former (6.9\% lower). Given the above, it is possible to suggest that lithium mining activities could have contributed to destress the water availability in the basin during the period between 2002 and 2017. Yet, this result is not necessarily extendable to the future and should be taken carefully into account due to the complexity of the Salar de Atacama's hydrological cycle. Therefore, more research is required to confidently sustaining that lithium mining activities can contribute to destress the basin.

\section{$\underline{5.2 \text { Future Technologies }}$}

New technologies for extracting lithium from brine aim to increase lithium recovery, from the current $60 \%$ to more than a $90 \%$ (Bian et al., 2017; Calvo, 2019; Liu et al., 2019; Zhao et al., 2019a). These technologies are expected to reduce the rate of pumped brine as they increase lithium production. Brine pumping reduction in the Salar de Atacama would deplete the risk of environmental negative effects over the delicate ecosystem. From the perspective of the use of the mineral deposit, a reduction in brine pumping rate would improve selectivity so higher ore grades could be extracted reducing in this way the cost of use or Hotelling rent of the deposit and so increasing the life of the mine (Guzmán, 2019).

The change in processing technologies for lithium extraction from the Salar de Atacama should not be evaluated without considering the unique characteristics of this deposit. As a matter of fact, as it is discussed in Flexer et al. (2018) future technologies to be implemented in the brine extraction industry must consider chemistry and geology of 
individual deposits to be effective. This point is specially critic since all brines are different in terms of composition and physical parameters (Munk et al., 2016).

Unfortunately, new productive technologies have several requirements that could affect the environmental sustainability of the activity. In general terms, they require either: (1) extensive freshwater consumption; (2) the use of chemical reagents, resulting in potential brine and surrounding habitats' pollution; or (3) significant amounts of brine that would carry additional trace elements to be reinjected in the deposit, with unknown effects in the dynamics of playas and adjacent ecosystems (Flexer et al., 2018). The latter is key since there are no studies about the reaction of a salt flat to a significant reinjection rate of brines, which could potentially affect the delicate equilibrium in the saline-freshwater interface depending on the location of reinjection.

If companies operating at the Salar de Atacama change the extraction and processing technology in the future, the hydric footprint of lithium production will undoubtedly change. So, any potential change in technology of extraction and/or processing should be evaluated in regard to its impact on the hydric stress of the basin.

\section{Conclusions}

The soaring lithium demand, driven by the electric vehicle market, has created a strong incentive to boost lithium supply. This has also been the case at Salar de Atacama, the largest and highest-grade lithium deposit under exploitation.

This paper has shown on a statistical basis that the total response to the impulse of brine extraction in the period from January 1986 to December 2018 explains, in average, a $20.5 \%$ (or $8.6 \mathrm{~mm} / \mathrm{month}$ ) of the precipitations registered at Salar de Atacama basin during this period. This means that brine evaporation linked with the mining of lithium (and 
potash) would have contributed in this percentage to the basin's recharge. Additionally, with a confidence level of $95 \%(p<0.05)$ the VAR model suggests that at least $1.2 \%$ and as much as 39.8\% of total precipitations in the Salar de Atacama basin could be explained due to evaporation ponds linked to the mining activity of potash and lithium extraction. Translating the precipitations in terms of recharge, the results show that the contribution to the basin ranges between $69 \mathrm{l} / \mathrm{s}$ and 1,375 l/s of added recharge to the counterfactual scenario of no mining at Salar de Atacama.

Considering the $180 \mathrm{l} / \mathrm{s}$ of water consumption and the $723 \mathrm{l} / \mathrm{s}$ of average recharge response to brine pumping impulse, the lithium mining in the Salar de Atacama contributes to the basin's recharge more water than it consumes. In this context, if the anthropogenic activities in the Salar de Atacama during the period 2002-2017 are quantified, the results show that the mining-free scenario would have heavily exploited the basin in terms of water stress, while the factual scenario would have only moderately stressed the basin. Yet, these results should be complemented with further information and investigations, as the hydrological cycle of the Salar de Atacama is a complex system and potentially more variables could have a role.

To improve the understanding of the counterfactual scenario of no exploitation over the ecosystem and the hydrological cycle in the Salar de Atacama basin, it could be of interest to pursue more research to narrow down the current ranges of solar evaporation rate. While the local effect at the basin level is the main concern that affects local communities and most stakeholders, checking the exohydric behavior of the system is a relevant matter for future research. To complement and fulfill a study on this topic certain critical points should be taken into account: (1) changes in natural evaporation; (2) isotopic studies to determine the origin of the precipitated water; and (3) eventual natural 
compensation responses of the hydrological cycle of the basin in absence of a brine extraction impulse. Moreover, additional efforts could be made to complement or expand the model presented here, incorporating regional and/or global processes that could also affect the water availability in the basin.

To assure the sustainability of the lithium extraction industry in the Salar de Atacama, those involved need to pay special attention on the preservation of the delicate ecosystem surrounding the exploitation area. Thus, hydrogeological models should be improved to establish, with a higher precision, the maximum sustainable pumping rate of brine. Considering this information, new technologies mostly focusing on increasing lithium recovery from extracted brine should be implemented in the Salar de Atacama only if they prove to be equally or less hydric stressful in comparison to the current extractive technology. The future of the sustainability of the battery electric vehicle market depends on it.

$\underline{\text { Code availability }}$

The Eviews file used in this study to estimate the VAR model are available from the corresponding author on request.

Data availability

The data sets are available from the corresponding author upon request.

\section{Acknowledgements}


The authors are grateful to SQM for providing the necessary data, some cited documents, as well as estimations of the sensibility of the water recharge in the Salar de Atacama basin in response to changes in precipitation (Figure 7).

\section{References}

Aitken, D., Rivera, D., Godoy-Faúndez, A., Holzapfel, E., 2016. Water scarcity and the impact of the mining and agricultural sectors in Chile. Sustainability 8(2), 128. $\underline{\text { https://doi.org/10.3390/su8020128 }}$

Amphos, 2018a. Modelo Hidrogeológico Consolidado Cuenca del Salar de Atacama. Comité de Minería no Metálica de CORFO.

Amphos, 2018b. Estudio de modelos hidrogeológicos conceptuales integrados para el Salar de Atacama. Comité de Minería no Metálica de CORFO.

Awotwi, A., Anornu, G., Quaye-Ballard, J., Annor, T., Forkuo, E., 2017. Analysis of climate and anthropogenic impacts on runoff in the Lower Pra River Basin of Ghana. Heliyon 3, e00477. 10.1016/j.heliyon.2017.e00477

Bai, Y., Qi, H., Zhao, T., Zhou, Y., Liu, L., Xiong, J., Zhou, Z., Cui, C., 2020. Simulation of the responses of rainstorm in the Yangtze River Middle Reaches to changes in 
anthropogenic aerosol emissions. Atmospheric Environment, 220, 117081. https://doi.org/10.1016/j.atmosenv.2019.117081

Baspineiro, C., Franco, J., Flexer, V., 2020. Potential water recovery during lithium mining from high salinity brines. Science of the Total Environment 720, 137523. https://doi.org/10.1016/j.scitotenv.2020.137523

BBC., 2019. Cómo la apuesta de Chile por el litio está desatando una disputa por el agua en Atacama. https://www.bbc.com/mundo/noticias-america-latina-49394020 (accessed 23 February 2021).

Bian, S., Li, D., Gao, D., Peng, J., Dong, Y., LI, W., 2017. Hydrometallurgical processing of lithium, potassium, and boron for the comprehensive utilization of Da Qaidam lake brine via natural evaporation and freezing. Hydrometallurgy 173, 80-83. https://doi.org/10.1016/j.hydromet.2017.07.008.

Bobst, A., Lowenstein, T., Jordan, T., Godfrey, L., Ku, T.-L., Luo, S., 2001. A 106 ka paleoclimate record from drill core of the Salar de Atacama, northern Chile. Palaeogeography, Palaeoclimatology, Palaeocology 173, 21-42. https://doi.org/10.1016/S0031-0182(01)00308-X.

Calvo, E., 2019. Electrochemical methods for sustainable recovery of lithium from natural brines and battery recycling. Current Opinion in Electrochemistry 15, 102-108. https://doi.org/10.1016/j.coelec.2019.04.010. 
Deutsche Welle., 2018. Chile: Explotación de litio deja sin agua a pobladores. https://p.dw.com/p/3WsYe. (accessed 23 February 2021).

Dirección de Estudios y Políticas Públicas., 2019. Proyección de consumo de agua en la minería del cobre 2019-2030 - DEPP 23/2019. https://www.cochilco.cl/Listado\%20Temtico/proyeccion\%20agua\%20mineria\%20del\%20c obre\%202019-2030\%20VF.pdf. (accessed 10 February 2021).

DGA., 2013. Análisis de la oferta hídrica del Salar de Atacama. Santiago, Chile. http://bibliotecadigital.ciren.cl/bitstream/handle/123456789/25996/HUM20115.pdf?sequence=1\&isAllowed=y. (accessed 10 February 2021).

Elsanabary, M., Gan, T., 2015. Evaluation of climate anomalies impact on the Upper Blue Nile Basin in Ethiopia using a distributed and lumped hydrologic model. Journal of Hydrology 530, 225-240. https://doi.org/10.1016/j.jhydrol.2015.09.052.

Feng, X., Zhang, X., Feng, Z., Wei, Y., 2019. Analyzing moisture-heat coupling in wheat-soil system using data-driven vector autoregression model. PeerJ 7:e7101. DOI: 10.7717/peerj.7101.

Finstad, K., Pfeiffer, M., McNicol, G., Barnes, J., Demergasso, C., Chong, G., Amundson, R., 2016. Rates and geochemical processes of soil and salt crust formation in Salars of the Atacama Desert. Geoderma 288, 57-72. https://doi.org/10.1016/j.geoderma.2016.08.020. 
Flexer, V., Baspineiro, C., Galli, C., 2018. Lithium recovery from brines: A vital raw material for green energies with a potential environmental impact in its mining and processing. Science of the Total Environment 639, 1188-1204.

https://doi.org/10.1016/j.scitotenv.2018.05.223.

Froelich, K., Kralik, M., Papesch, W., Rank, D., Scheifinger, H., 2008. D-excess in precipitation of Alpine region-moisture recycling. Isotopes in Environmental and Health Studies 44, 61-70

Gajardo, G., Redón, S., 2019. Andean hypersaline lakes in the Atacama Desert, northern Chile: Between lithium exploitation and unique biodiversity conservation. Conservation Science and Practice 1, e94. https://doi.org/10.1111/csp2.94.

Garcés, I., Álvarez, G., 2020. Water mining and extractivism of the Salar de Atacama. Working Paper, Universidad de Antofagasta.

Garret, D., 2004. Handbook of lithium and natural calcium chloride. Elsevier Academic Press, Oxford. 
Gat, J., Bowser, C., Kendall, C., 1994. The contribution of evaporation from the Great Lakes to the continental atmosphere: Estimate based on stable isotope data. Journal of Geophysical Research 96, 13179-13188. https://doi.org/10.1029/94GL00069.

Granger, C. W. J., 1969. Investigating causal relations by econometric models and crossspectral methods. Econometrica 37, 424-438. https://doi.org/10.2307/1912791.

Guzmán, J.I., 2019. Fundamentos de economía minera. Editorial Reverté, Barcelona.

Habib, K., Hansdóttir, S.T., Habib, H., 2020. Critical metals for electromobility: Global demand scenarios for passenger vehicles, 2015-2050. Resources, Conservation \& Recycling 154, 104603. https://doi.org/10.1016/j.resconrec.2019.104603.

Hölting, B., Coldewey, W., 2019. Hydrogeology. Springer, Berlin.

Houston, J., 2006. Evaporation in the Atacama Desert: An empirical study of spatiotemporal variations and their causes. Journal of Hydrology 330, 402-412. https://doi.org/10.1016/j.jhydrol.2006.03.036.

Houston, J. Butcher, A., Ehren, P., Evans, K., Godfrey, L., 2011. The evaluation of brine prospects and the requirement for modifications to filing standards. Economic Geology 106, 1225-1239. https://doi.org/10.2113/econgeo.106.7.1225.

Hylleberg, S., 1986. Seasonality in regression. Academic Press, Orlando. 
Kampf, S., Tyler, S., Ortiz, C., Muñoz, J., Adkins, P., 2005. Evaporation and land surface energy budget at the Salar de Atacama, Northern Chile. Journal of Hydrology 310, 236252. https://doi.org/10.1016/j.jhydrol.2005.01.005.

Kesler, S., Gruber, P., Medina, P., Keoleian, G., Everson, M., Wallington, T., 2012. Global lithium resources: Relative importance of pegmatite, brine and other deposits. Ore Geology Reviews 48, 55-69. https://doi.org/10.1016/j.oregeorev.2012.05.006.

Kilian, L., Lütkephol, H., 2017. Structural vector autoregressive analysis. Cambridge University Press, New York.

Kong, Y., Pang, Z., Froehlich, K., 2013. Quantifying recycled moisture fraction in precipitation of an arid region using deuterium excess. Tellus B 65, 19251. https://doi.org/10.3402/tellusb.v65i0.19251.

Kundzewicz., Z., 2008. Climate change impacts on the hydrological cycle. Ecohydrology \& Hydrobiology 8 (2-4), 195-203. https://doi.org/10.2478/v10104-009-0015-y.

Liu, G., Zhao, Z., Ghahreman, A., 2019. Novel approaches for lithium extraction from saltlake brines: A review. Hydrometallurgy 187, 81-100. https://doi.org/10.1016/j.hydromet.2019.05.005. 
Liu, W., Agusdinata, D., 2020. Interdependencies of lithium mining and communities sustainability in Salar de Atacama, Chile. Journal of Cleaner Production 260, 120838. https://doi.org/10.1016/j.jclepro.2020.120838.

Lütkephol, H., 2006. New introduction to multiple time series analysis. Springer-Verlag, Berlin.

Machavaram, V., Krishnamurthy, M., 1995. Earth surface evaporative process: a case study from the Great Lakes region of the United States based on deuterium excess in precipitation. Geochimica et Cosmochimica Acta 59, 4279-4283. https://doi.org/10.1016/0016-7037(95)00256-Y.

Mangiarotti, S., Sekhar, M., Berthon, L., Javeed, Y., Mazzega, P., 2012. Causality analysis of groundwater dynamics based on a Vector Autoregressive model in the semi-arid basin of Gundal (South India). Journal of Applied Geophysics 83, 1-10.

https://doi.org/10.1016/j.jappgeo.2012.04.003.

Marazuela, M.A., Vázquez-Suñé, E., Ayora, C., García-Gil, A., Palma, T., 2019a. The effect of brine pumping on the natural hydrodynamics of the Salar de Atacama: The damping capacity of salt flats. Science of the Total Environment 654, 1118-1131. https://doi.org/10.1016/j.scitotenv.2018.11.196. 
Marazuela, M.A., Vázquez-Suñé, E., Ayora, C., García-Gil, A., Palma, T., $2019 b$.

Hydrodynamics of salt flat basins: The Salar de Atacama example. Science of the Total Environment 651, 668-683. https://doi.org/10.1016/j.scitotenv.2018.09.190.

Marazuela, M.A., Vázquez-Suñé, E., Ayora, C., García-Gil, A., 2020. Towards more sustainable brine extraction in salt flats: Learning from the Salar de Atacama. Science of the Total Environment 703, 135605. https://doi.org/10.1016/j.scitotenv.2019.135605.

Mardones, L., 1998. Flux et evolution des solutions salines dans les systemes hydrologiques des salars d'Asoctan et d'Atacama. PhD Dissertation, 278, University of Paris.

Mudd, G., 2008. Sustainability Reporting and Water Resources: A Preliminary Assessment of Embodied Water and Sustainable Mining. Mine Water Environment 27, 136-144. https://doi.org/10.1007/s10230-008-0037-5.

Munk, L., Hynek, S., Bradley, D., Boutt, D., Labay, K., Jochens, H., 2016. Lithium Brines: A Global Perspective. Reviews in Economic Geology 18, 339-365.

Munk, L., Boutt, D., Moran, B., McKnight, S., Jenckes, J., 2020. Hydrogeologic and geochemical distinctions in salar freshwater brine systems. Geochemistry, Geophysics, Geosystems (forthcoming). https://doi.org/10.31223/osf.io/j3pu6. 
Nilsalab, P., Gheewala, S., Silalertruska, T., 2016. Methodology development for including environmental water requirement in the water stress index considering the case of Thailand. Journal of Cleaner Production 167, 1002-1008.

https://doi.org/10.1016/j.jclepro.2016.11.130.

Peng, T., Liu, K., Wang, C., 2011. A water isotope approach to assessing moisture recycling in the island-based precipitation of Taiwan: a case study in the western Pacific. Water Resources Research 47, W08507. https://doi.org/10.1029/2010WR009890.

Pöyry., 2020. Life Cycle Assessment (LCA) for lithium products. Sociedad Química y Minera SQM.

Ramli, I., Rusdiana, S., Basri, H., Munawar, A.A., Azelia, V., 2019. Predicted Rainfall and discharge Using Vector Autoregressive Models in Water Resources Management in the High Hill Takengon. Earth and Environmental Science 273, 012009.

Reuters., 2018. A water fight in Chile's Atacama raises questions over lithium mining. https://www.reuters.com/article/us-chile-lithium-insight/a-water-fight-in-chiles-atacamaraises-questions-over-lithium-mining-idUSKCN1MS1L8. (accessed 10 February 2021)

Russo, T., Lall, U., 2017. Depletion and response of deep groundwater to climate-induced pumping variability. Nature Geoscience 10, 105-108. 
Shao, X., Fang, Y., Cui, B., 2020. A model to evaluate spatiotemporal variations of hydrological connectivity on a basin-scale complex river network with intensive human activity. Science of the Total Environment 723, 138051.

https://doi.org/10.1016/j.scitotenv.2020.138051.

Salvucci, G., Saleem, J., Kaufmann, R., 2002. Investigating soil moisture feedbacks on precipitation with tests of Granger causality. Advances in Water Resources 25, 13051312.https://doi.org/10.1016/S0309-1708(02)00057-X.

Sasikumar, R., Indira, S., 2019. The impact of seasonal variation in ground water level using vector autoregressive model. The International Journal of Analytical and Experimental Modal Analysis 11, 1611-1618.

Scafetta, N., 2010. Empirical evidence for a celestial origin of the climate oscillations and its implications. Journal of Atmospheric and Solar-Terrestrial Physics 72, 951-970. https://doi.org/10.1016/j.jastp.2010.04.015.

Seneviratne, S. I., Corti, T., Davin, E. L., Hirschi, M., Jaeger, E. B., Lehner, I., Teuling, A. J., 2010. Investigating soil moisture-climate interactions in a changing climate: A review. Earth-Science Reviews, 99(3-4), 125-161. https://doi.org/10.1016/j.earscirev.2010.02.004.

Smakhtin, V., Revenga, C., Döll, P., Tharme, R., Nackoney, J., Kura., 2004. Taking into account environmental water requirements in global-scale water resources assessments. 
Comprehensive Assessment Secretariat. Colombo, Sri Lanka.

Sovacool, B., Ali, S., Bazilian, M., Radley, B., Nemery, B., Okatz, J., Mulvaney, D., 2020.

Sustainable minerals and metals for a low-carbon future. Science, 367 (6473), 30-33. DOI:

10.1126/science.aaz6003.

SQM., 2019. Sustainability Report 2019. https://www.sqm.com/en/sustentabilidad/reportede-sustentabilidad/. (accessed 30 January 2021)

SQM., 2020. Modelo hidrogeológico conceptual del Salar de Atacama. Document prepared for EIA. (accessed 30 January 2021).

Subsecretaría de Turismo., 2018. Primer Estudio Longitudinal de Turismo Interno del país. http://www.subturismo.gob.cl/. (accessed 10 January 2021).

Tejeda, I., Cienfuegos, R., Muñoz, J., Durán, M., 2003. Numerical modeling of saline intrusion in Salar de Atacama. Journal of Hydrologic Engineering 8(1), 25-34.

Toda, H. Y., Yamamoto, T., 1995. Statistical inference in vector autoregressions with possibly integrated processes, Journal of Econometrics 66, 225-250.

https://doi.org/10.1016/0304-4076(94)01616-8. 
Umar, D., Ramli, M., Aris, A., Jamil, J., Aderemi, A., 2019. Evidence of climate variability from rainfall and temperature fluctuations in semi-arid region of the tropics. Atmospheric Research 224, 52-64. https://doi.org/10.1016/j.atmosres.2019.03.023.

Van der Ent, R., Savenije, H., Schafelli, B., Steele-Dunne, S., 2010. Origin and fate of atmospheric moisture over continents. Water Resources Research 46, W09525. https://doi.org/10.1029/2010WR009127.

Vásquez, C., Ortiz, C., Suárez, F., Muñoz, J., 2013. Modeling flow and reactive transport to explain mineral zoning in the Atacama salt flat aquifer, Chile. Journal of Hydrology 490, 114-125. https://doi.org/10.1016/j.jhydrol.2013.03.028.

Verruijt, A., 1968. A note on the Ghyben-Herzberg formula. Bulletin - International Association of Scientific Hydrology 13, 43-46.

Wang, G., Zhang, J., He, R., Naiqian, J., Jing, X., 2008. Runoff reduction due to environmental changes in the Sanchuanhe river basin. International Journal of Sediment Research 23, 174-180. https://doi.org/10.1016/S1001-6279(08)60017-7.

Warren, J., 2016. Evaporites: A geological compendium. Second edition. Basel: Springer, eBook.

Yang, Y., Wang, S., Bai, X., Tan, Q., Li, Q., Wu, L., Deng, Y., 2019. Factors affecting long-term trends in global NDVI. Forests, 10(5), 372. https://doi.org/10.3390/f10050372. 
Zhao, X., Yang, H., Wang, Y., Sha., 2019a. Review on the electrochemical extraction of lithium from seawater/brine. Journal of Electroanalytical Chemistry 850, 113389. https://doi.org/10.1016/j.jelechem.2019.113389.

Zhao, L., Liu, X., Wang, N., Kong, Y., Song, Y., He, Z., Wang, L., 2019b. Contribution of recycled moisture to local precipitation in the inland Heihe River Basin. Agricultural and Forest Meteorology, 271, 316-335. https://doi.org/10.1016/j.agrformet.2019.03.014.

Zongxing, L., Qi, F., Wang, Q. J., Yanlong, K., Aifang, C., Song, Y., Xiaoyan, G., 2016. Contributions of local terrestrial evaporation and transpiration to precipitation using $\delta 180$ and D-excess as a proxy in Shiyang inland river basin in China. Global and Planetary Change, 146, 140-151. https://doi.org/10.1016/j.gloplacha.2016.10.003. 


\section{Figures}

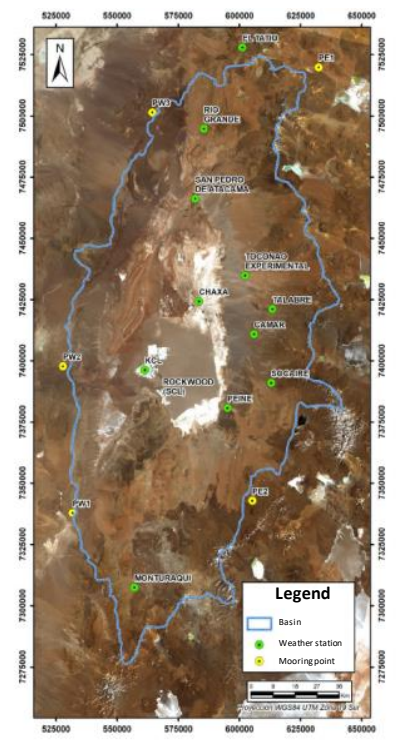

Figure 1. Weather stations overview at Salar de Atacama basin. Light blue line delimits the SdA basin frontier. Weather stations are represented by green points.

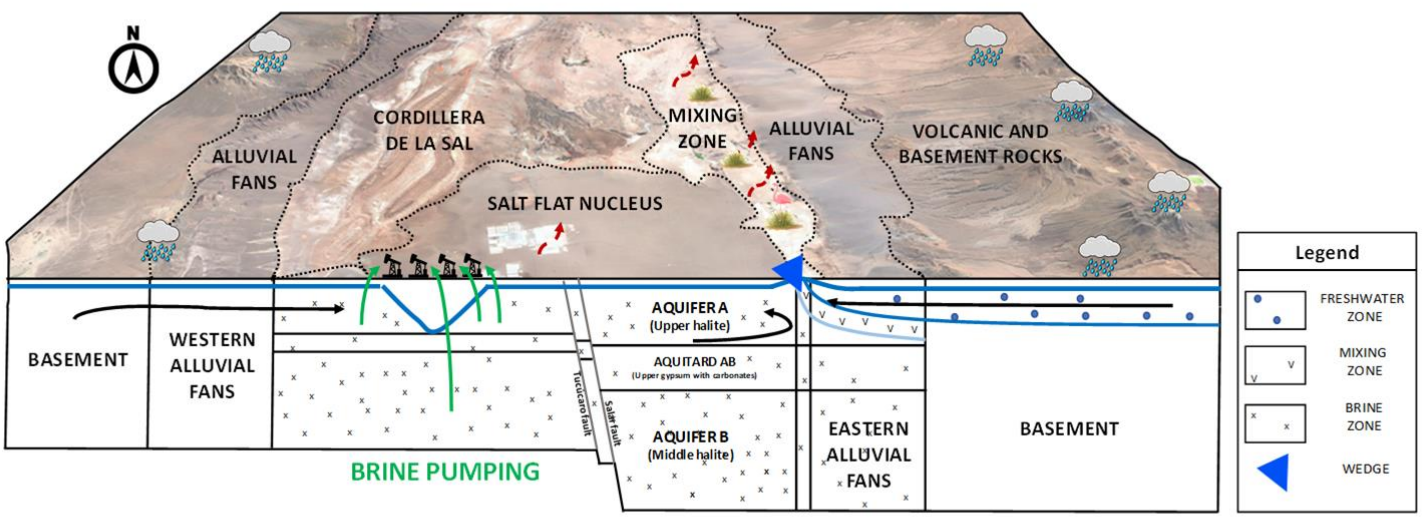

Figure 2. Conceptual model of Salar de Atacama basin 


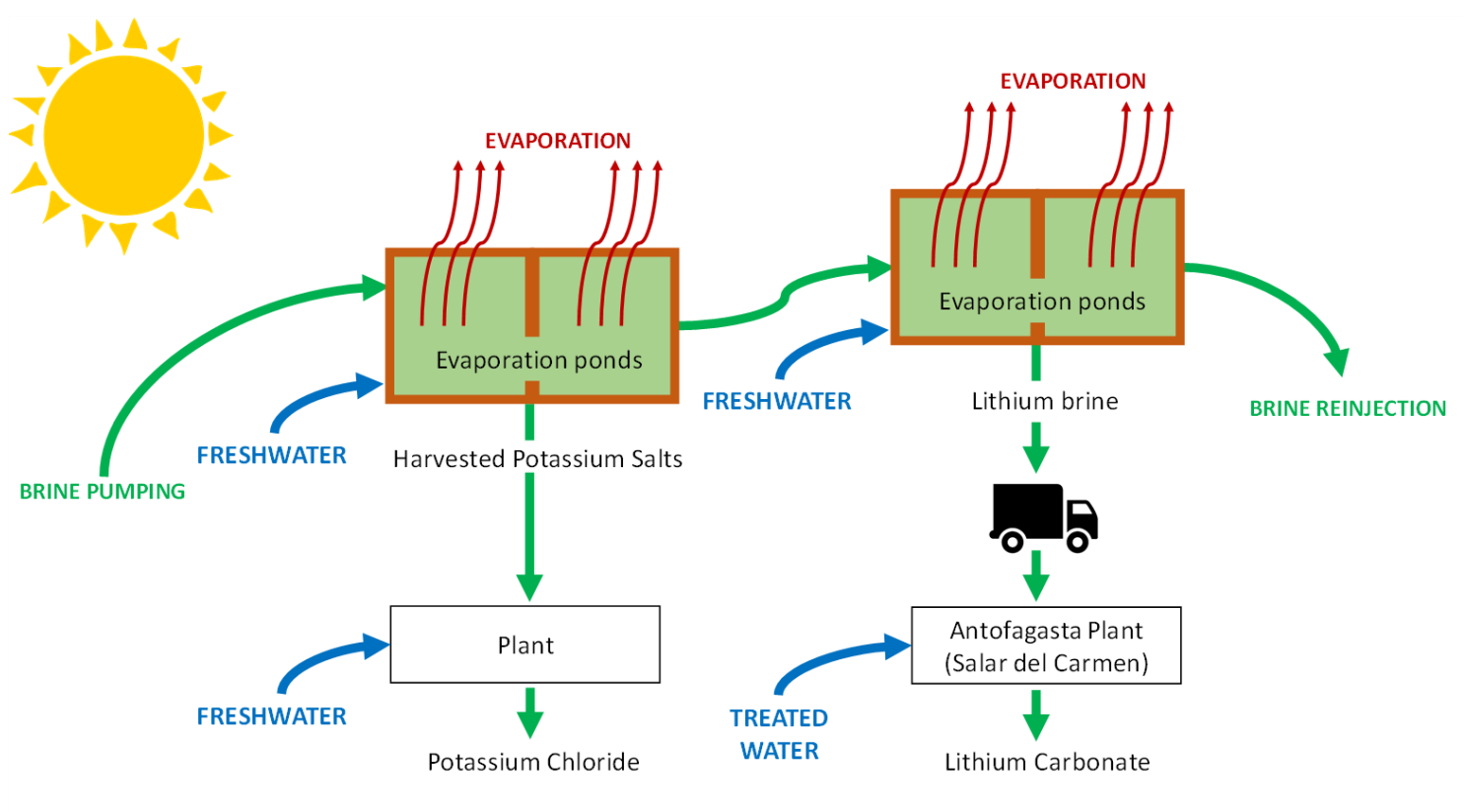

Figure 3. Lithium and potassium flowsheet production at Salar de Atacama

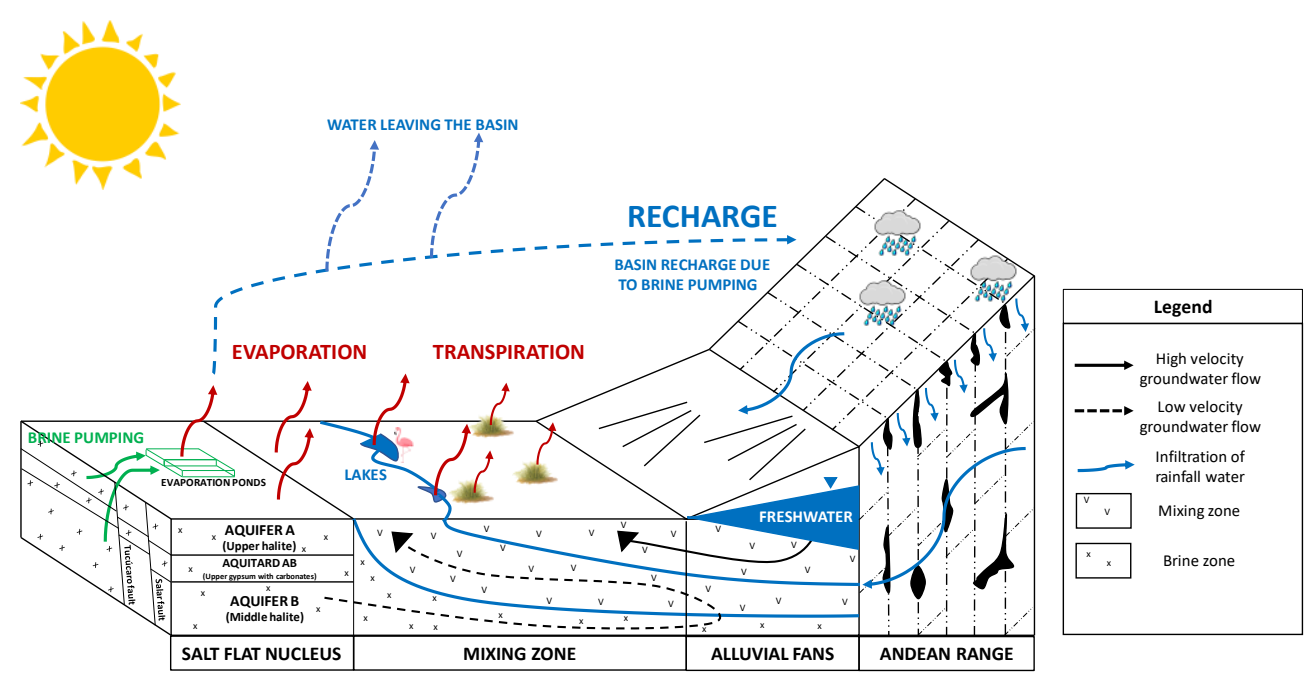

Figure 4. Conceptual hydrological cycle in the Salar de Atacama basin. Blue dashed arrows represent the recharge due to brine pumping and the evaporated water leaving the basin. Red continuous arrows show the evapotranspiration and green continuous arrows show the brine pumping that goes to evaporation ponds. It is shown that brine pumping occurs at salt flat nucleus in aquifers $\mathrm{A}$ and $\mathrm{B}$ which are separated by aquitard $\mathrm{AB}$. 

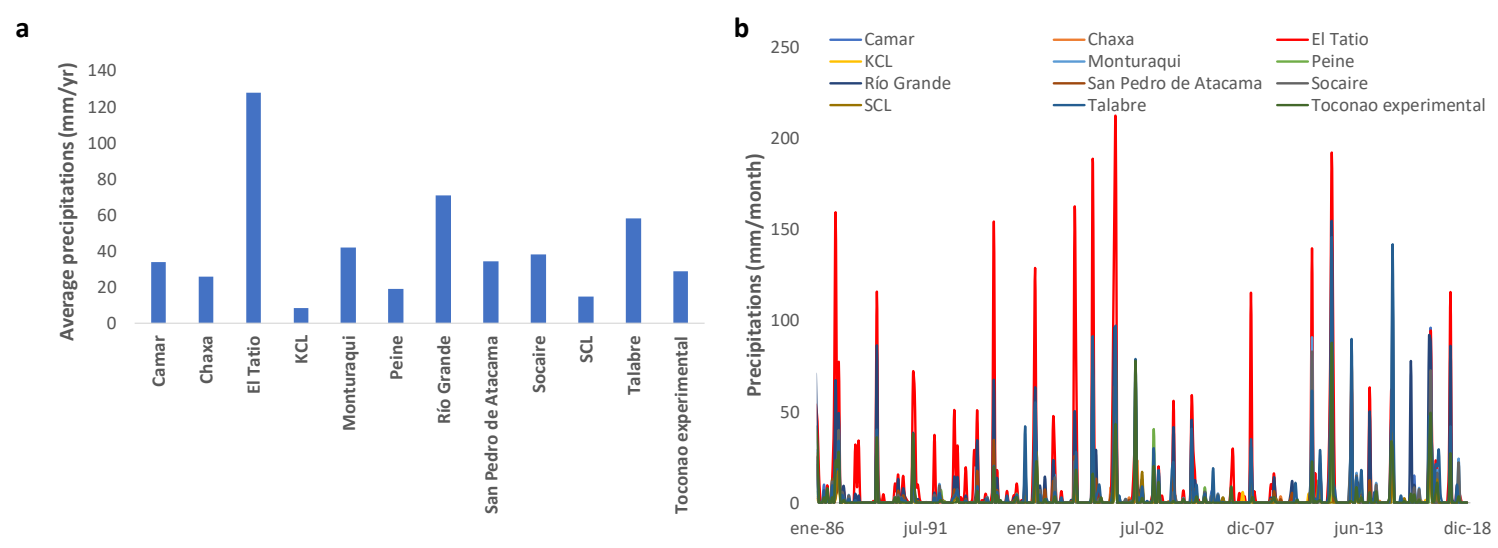

Figure 5. Precipitations measured by weather stations. a, Bars show the average precipitations (mm/yr) for each weather station between January 1986 to December 2018.

b, Lines shows the precipitations ( $\mathrm{mm} / \mathrm{month}$ ) evolution of each weather station.

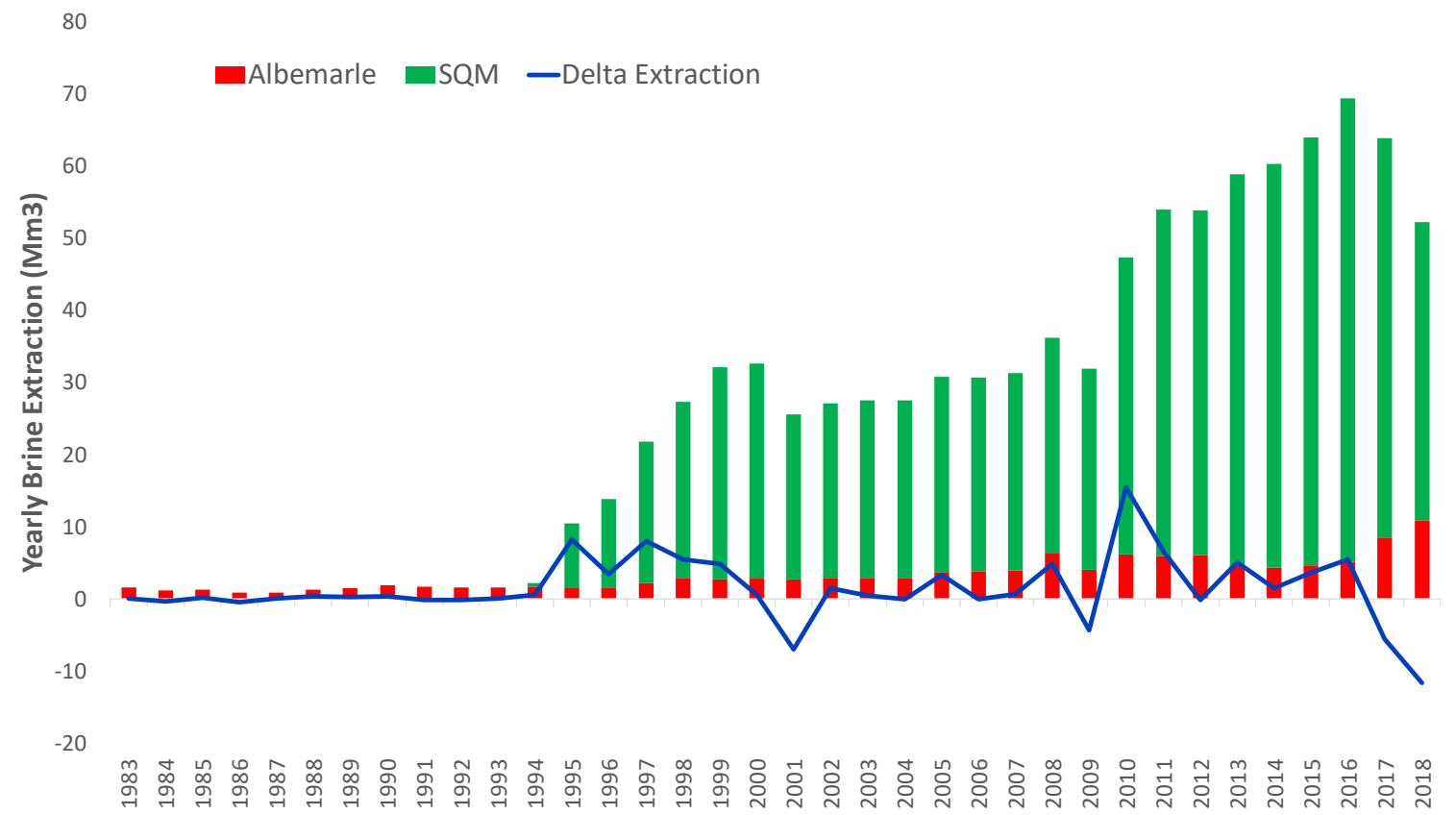


Figure 6. Yearly brine extraction at Salar de Atacama by SQM and Albemarle (SQM, 2020). Blue continuous line shows the annual variation in extraction of brines (for both companies)

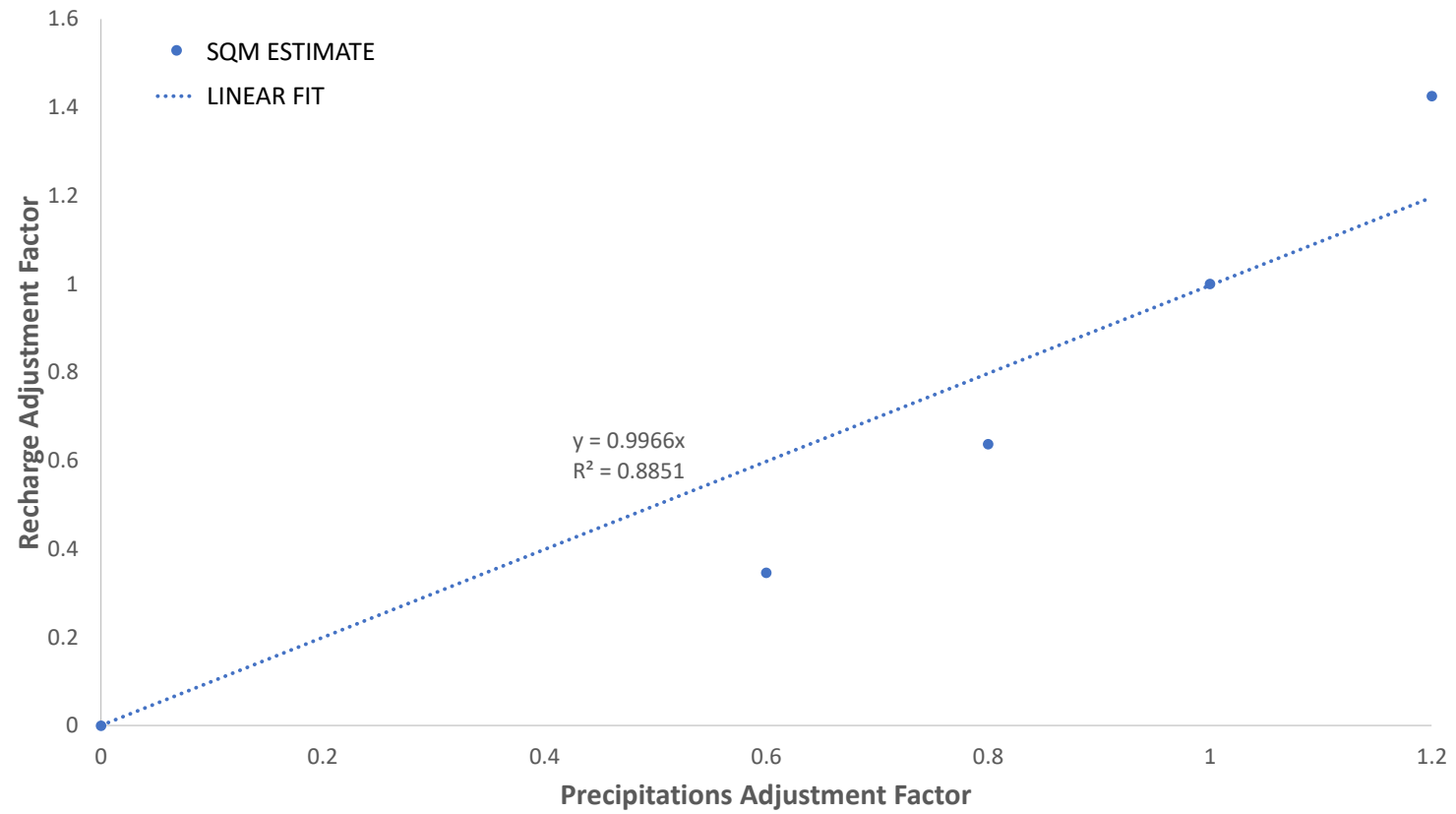

Figure 7. Salar de Atacama basin recharge response to changes in precipitations estimated by SQM 
a

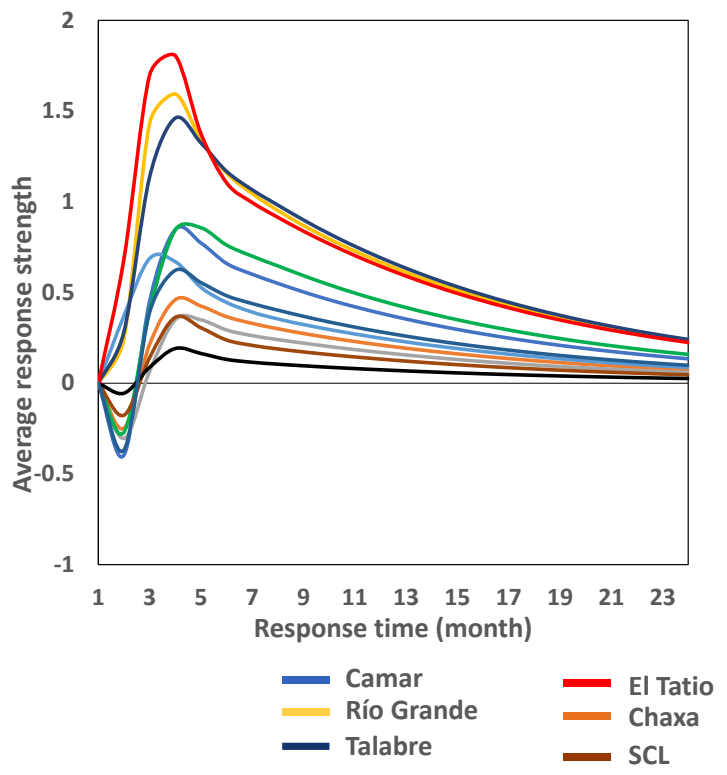

b

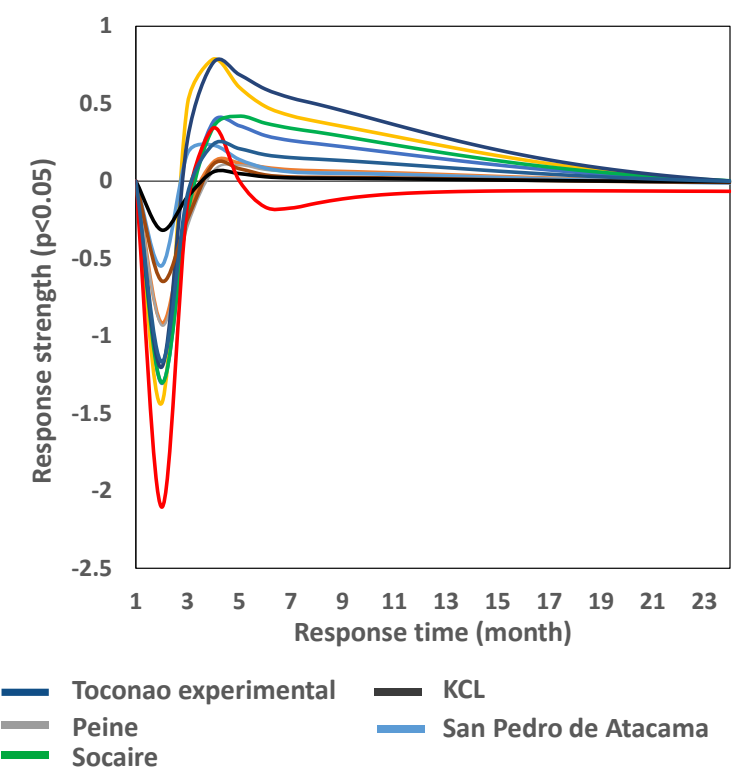

Figure 8. Precipitation response to extraction of brines. Curves show the response in precipitations (in terms of standard deviation) for each weather station in a monthly base, given an impulse of brine extraction. (a) shows average results, whilst (b) shows the results within a $95 \%$ of confidence 


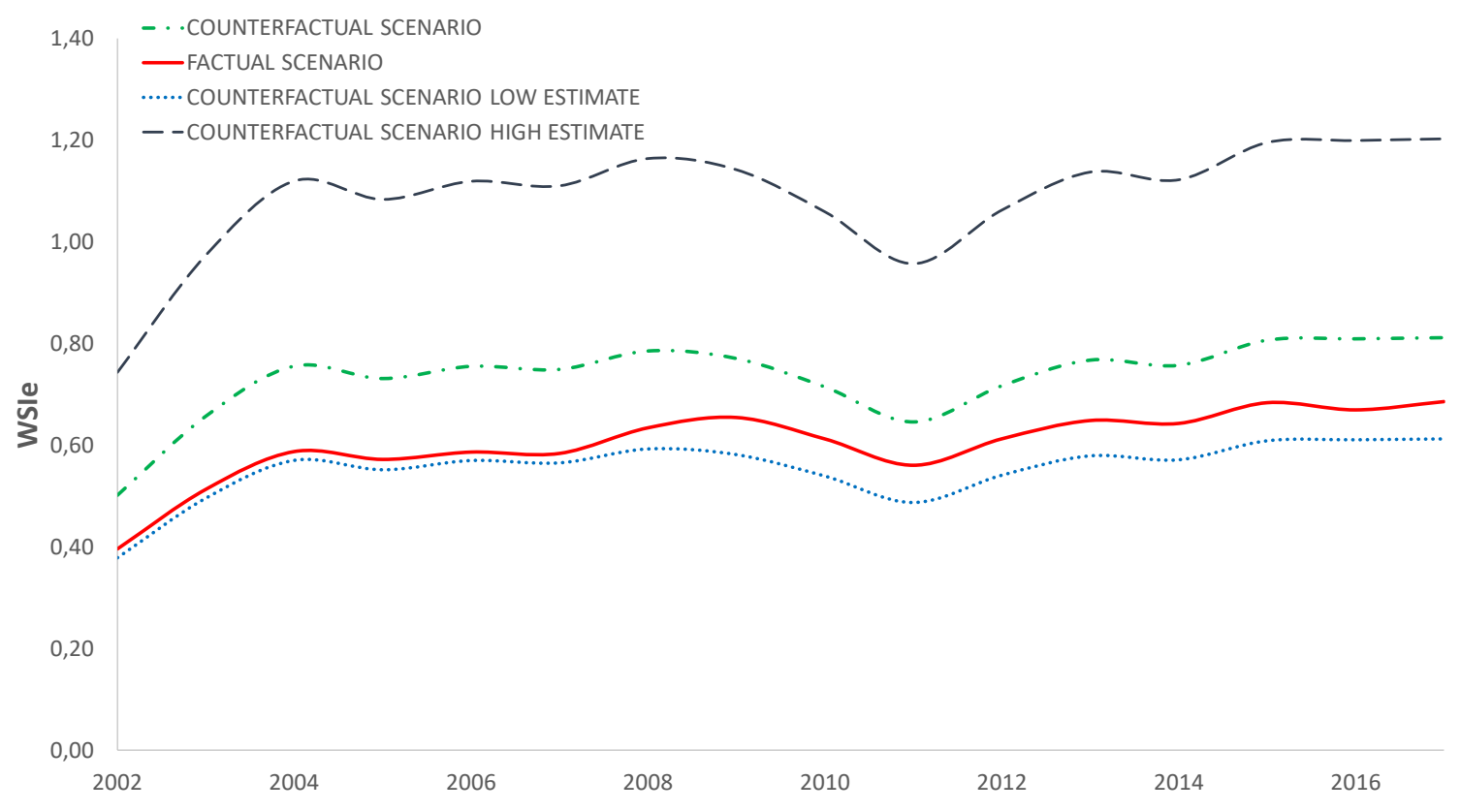

Figure 9. $W S I_{e}$ for factual and counterfactual (i.e., no mining) scenarios at Salar de Atacama 